\title{
A pertinência da Medicina Narrativa na prática clínica
}

Isabel Fernandes*

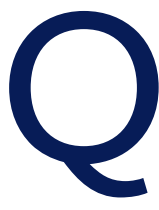

uando, há meses, recebi o convite da Directora desta revista, Dr. Paula Broeiro, para abordar o tema da Medicina Narrativa (MN), " além de me sentir muito honrada e agradecida pela confiança em mim depositada, experimentei simultaneamente algum constrangimento, pois o espaço atribuído a um editorial não permite fazer jus ao muito que há a dizer sobre o tema. Entendam, pois, os leitores o que se segue como esboço meramente introdutório.

Falar da novidade da abordagem narrativa nas práticas de saúde é incorrecto e injusto. Desde o célebre triângulo hipocrático - médico/doença/doente - que a narrativa da doença por parte do último foi reconhecida como elemento integrante do encontro clínico. Não se trata, pois, de novidade. Contudo, ao arrepio desta longa tradição, a evolução histórica da prática médica recente, sobretudo a partir da Escola Clínica de Paris (1789), acentuou o pendor cientificizante, de cunho positivista e valorizador do regime dos factos que marcou um novo modo de entender e praticar medicina, actuante até aos nossos dias, em que o relato do doente foi perdendo terreno. Naquilo que pensadores como Michel Foucault ${ }^{1}$ caracterizam como um momento novo em termos epistemológicos, ${ }^{\dagger}$ passam a reconhecer-se apenas como factos clínicos os dados objectivos, encarados como os únicos fiáveis. É com factos que o médico lida e tudo o que o não seja é menosprezado. Valores religiosos ou crenças de índole cultural, por exemplo, são desvalorizados. Tais aspectos, em geral, não se detectam pela observação objectiva; só podem ser veiculados oralmente - quando muito poderão emergir na anamnese, mas este éjustamente o momento hoje menos valorizado do encontro clínico. Para ultrapassar esta depreciação, é necessário rever o conceito de história clínica, reconhecendo-o como um relato que vai ser decisivo para uma deliberação. Ora, a deliberação não serve para coisas demonstráveis, antes se aplica à incerteza, ao que não é totalmente racional - as decisões penden-

*Professora Catedrática da FLUL - Faculdade de Letras da Universidade de Lisboa Responsável Científica pelo Projecto Medicina \& Narrativa - (Con)textos e práticas interdisciplinares [Ref. PTDC/CPC-ELT/3719/2012], do CEAUL/ULICES - Centro de Estudos Anglísticos da Universidade de Lisboa, financiado pela FCT (Fundação para a Ciência e a Tecnologia). tes. Tal requer implicar o doente, ouvi-lo e conceder-lhe autonomia - esta é, para Diego Grácia, a "atitude ética" que deve caracterizar a clínica. ${ }^{\ddagger}$

João Lobo Antunes, ${ }^{2}$ em obra recente, manifesta a sua admiração com os extraordinários progressos alcançados pela medicina, sobretudo ao longo da segunda metade do séc. $\mathrm{XX}$. Mas, simultaneamente, teme que se tenha desincentivado a escuta do relato do doente (o médico interrompe-o, em média, ao fim de 18 segundos), que se desvalorize a observação física em favor dos meios auxiliares de diagnóstico e assim se perca de vista a singularidade de cada caso clínico, que tendencialmente passa a ser encarado como mera ilustração dum caso tipificado e enquadrado por dados estatísticos. ${ }^{2: 29-30}$ Por aí se confunde a singularidade biológica do doente (sem dúvida crucial) com a, não menos importante, individualidade deste, a qual, segundo o autor, deve continuar a estar também no cerne da atenção do clínico.

Por reacção a este quadro, tem-se desenvolvido a MN que procura combater as tendências atrás descritas, ao mesmo tempo que ultrapassa a medicina hipocrática e a positivista pela agência que concede ao doente. Mas quando surgiu e o que traz de novo a $\mathrm{MN}$ ?

Ainda que tenha havido manifestações de insatisfação e mal-estar perante este estado de coisas, já na década de 50 do século passado ${ }^{\S}$ e, sobretudo nas décadas de 80 e 90 do mesmo século, que se fizeram notar de forma mais decidida publicações e iniciativas conducentes a um movimento que hoje se manifesta a nível mundial, mas muito em par-

\footnotetext{
* O texto aqui apresentado resulta de investigação desenvolvida no âmbito do projecto Medicina \& Narrativa - (Con)textos e práticas interdisciplinares [Ref.PTDC/CPC-ELT/3719/2012], do CEAUL/ULICES - Centro de Estudos Anglísticos da Universidade de Lisboa, financiado pela FCT (Fundação para a Ciência e a Tecnologia), pelo qual a autora é responsável científica.

† Cf. Michel Foucault, Naissance de la clinique, onde o autor mostra como, nos séculos XVII e XVIII, se deu a consolidação da anatomia patológica como base epistemológica da medicina moderna (científica), ilustrando assim a profunda alteração que designa de "mudança de episteme." ‡ Neste passo baseio-me no conteúdo duma conferência proferida em Lisboa por Diego Gracia, em 29 de Março de 2011, no Centro de Saúde de Sete-Rios, no âmbito do ciclo de palestras e programa de formação promovidos pelo projecto Narrativa \& Medicina, do CEAUL/ULICES.
} 
ticular no mundo anglo-saxónico. Refiro-me ao aparecimento de programas como o da Universidade de Columbia - Program in Narrative Medicine (fundado em 2000) e publicações como as de Richard Zaner (1988), ${ }^{4}$ de Rita Charon $(1995)^{5}$ ou de Brian Hurwitz (1998). ${ }^{6}$

Para legitimar esta nova tendência, alegou-se que ela visava corrigir o quadro anterior em que se procedia como se os médicos fossem treinados para tratar qualquer situação médica como mero problema a ser resolvido, mas sem ter em conta os aspectos psicológicos e contextuais do doente (história de vida, crenças, medos, dilemas). Impunha-se um redireccionar da atenção da doença para o doente e uma reconsideração da relação médico/doente que revalorizasse a singularidade e o contexto específico de cada caso. Assim, a NM ou NBM (Narrative-based Medicine), como também foi chamada, surgia pouco depois do momento em que se institucionalizava a EBM (Evidence-based Medicine), no início dos anos 80 do séc. XX, sendo esta última responsável por consubstanciar um modelo "duro" de ciência médica.

Se Charon chama a atenção para a dimensão relacional e hermenêutica que define a MN, ao encará-la como uma medicina "praticada com a competência narrativa para reconhecer, interpretar e ser levado a agir pela situação crítica dos outros" 8:83 [tradução minha], já Hurwitz torna explícito um outro propósito ao encarar a MN como: "uma prática e uma atitude intelectual que permite aos médicos olhar para lá dos mecanismos biológicos no cerne das abordagens convencionais à prática médica, e abarcar domínios de pensamento e modos de dizer que se focalizam na linguagem e na representação, nas emoções e nas relações que iluminam a prática dos cuidados de saúde"3:73 [tradução minha]. Tal como este autor sublinha, não se trata de prescindir dos avanços da ciência médica, mas apenas de reconhecer que

\footnotetext{
$\$$ Na década de 50 do séc., XX, o aparecimento dos Grupos Balint sinalizava a existência dum mal-estar e da necessidade de o colmatar: reconhecendo que a consulta médica é, no essencial, um acto de relação, visavam amparar o clínico, fazendo-o partilhar inter pares os dilemas e dificuldades da sua relação com o doente concreto, visando criar uma relação de confiança entre ambos. Contudo e curiosamente, como assinala Brian Hurwitz, na obra de Michael Balint, The doctor, his patient and the illness (1957), não há qualquer referência à narrativa. Cf. Hurtwitz 2011:75.3

I Sobre a relação entre a NBM e a EBM veja-se, por exemplo, o meu artigo «O elefante verde ou a importância da Medicina Narrativa na prática clínica» (2014). ${ }^{7}$
}

ela só por si não será capaz de fornecer bases sólidas que preparem o médico para a complexidade dum genuíno e profícuo encontro com o seu doente.

Nesta óptica assume particular importância a narrativa, não apenas por estar no cerne do intercâmbio linguístico entre médico e doente, mas por poder ser ainda vista como instrumento formativo capaz de fornecer instrumentos interpretativos indispensáveis e promover uma atitude mais atenta e perspicaz aos modos de dizer (e de calar) do doente.

Apanágio desta nova área é ainda o facto de ela não prescindir duma dimensão multidisciplinar, congregando, pela primeira vez na história da medicina, os saberes de disciplinas humanísticas como a filosofia, os estudos literários, a linguística e a ética, por exemplo, para as suas intervenções, quer no plano formativo (formação de estudantes e formação contínua) quer ainda no plano profilático (por exemplo, na prevenção do burnout médico).

Conforme defende Charon, em obra de referência nesta nova área: "o treino narrativo ao nível da leitura e da escrita contribui para a eficácia clínica" ${ }^{9107}$ [tradução minha].

\section{REFERÊNCIAS BIBLIOGRÁFICAS}

1. Foucault M. Naissance de la clinique. 8e ed. Paris: PUF; 2009. ISBN 9782130578659

2. Lobo Antunes J. A nova medicina. Lisboa: Fundação Francisco Manuel dos Santos; 2012. ISBN 9789898424433

3. Hurtwitz B. Narrative (in) medicine. In Spinozzi P, Hurtwitz B, editors. Discourses and narrations in the biosciences. Göttingen: Vandenhoeck \& Ruprecht Unipress; 2011. p. 73-87.

4. Zaner RM. Ethics and the clinical encounter. Englewood Cliffs, New Jersey: Prentice Hall; 1988. ISBN 9780132905459

5. Charon R, Banks JT, Connelly JE, Hawkins AH, Hunter KM, Jones AH, et al. Literature and medicine: contributions to clinical practice. Ann Intern Med. 1995;122(8):599-606.

6. Hurwitz B, Greenhalgh T. Narrative-based medicine: dialogue and discourse in clinical practice. London: BMJ Books; 1998. ISBN 0727912232

7. Fernandes I. O elefante verde ou a importância da medicina narrativa na prática clínica. Rev Ordem Médicos. 2014;(153):76-81. Portuguese

8. Charon R. Narrative medicine: form, function, and ethics. Ann Intern Med. 2001;134(1):83-7.

9. Charon R. Narrative medicine: honoring the stories of illness. Oxford: Oxford University Press; 2006. ISBN 9780195340228

\section{CONFLITOS DE INTERESSE}

A autora declara não ter conflitos de interesse.

\section{ENDEREÇO PARA CORRESPONDÊNCIA}

narrativmedicin@gmail.com 